\title{
Non-uniform distribution of plastic strain in duplex steel during TEM in situ deformation
}

\author{
W. Zieliński ${ }^{\mathrm{a}, *}$, W. Świątnicki ${ }^{\mathrm{a}}$, M. Barstch ${ }^{\mathrm{b}}, \mathrm{U}$. Messerschmidt ${ }^{\mathrm{b}}$ \\ ${ }^{a}$ Faculty of Materials Science and Engineering, Warsaw University of Technology, Wotoska 141, 02-507 Warsaw, Poland \\ ${ }^{\mathrm{b}}$ Max Planck Institute of Microstructure Physics, Weinberg 2, D-06120 Halle, Germany
}

\begin{abstract}
Transmission electron microscopy (TEM) in situ straining experiments were carried out on duplex ferritic-austenitic steel. Localization of strain as a common feature during slip transfer from the austenite to the ferrite has been noticed. The character of strain localization depends on the orientation relationship between the phases. A possible influence of the TEM specimen geometry on the mechanism of plastic deformation of the ferritic-austenitic steel was considered by comparing the results with those of in situ straining experiments have been performed in a $1 \mathrm{MV}$ high-voltage TEM instrument.
\end{abstract}

(C) 2003 Elsevier Science B.V. All rights reserved.

Keywords: Ferritic-austenitic steel; TEM; In situ deformation; Strain localization

\section{Introduction}

Grain boundaries play a key role in the plastic deformation of polycrystalline materials. They restrict plastic deformation at room temperature, which leads to a build-up of internal stresses [1-3]. The ferritic-austenitic duplex steel possesses a specific microstructure, where the face centered cubic austenite $(\gamma)$ and the body-centered cubic ferrite $(\alpha)$ may create internal stresses during deformation due to their elastic and plastic incompatibilities.

According to the Kurdiumov-Sachs and NishijamaWassermann orientation relationships there are easy slip planes in the two phases which coincide, e.g. $\left\{\begin{array}{llll}1 & 1 & 1\end{array}\right\}_{\gamma} \|$ $\left\{\begin{array}{lll}1 & 10\end{array}\right\}_{\alpha}$. In the case of the Kurdiumov-Sachs relationship, one of the six easy slip directions in the austenite is parallel to the easy slip direction in the ferrite, i.e. $\langle 110\rangle_{\gamma} \|$ $\langle 111\rangle_{\alpha}$, while in the case of the Nishijama-Wassermann orientation relationship, they are slightly deviated (by $5.26^{\circ}$ ). Despite the special orientation relationships, also random orientation relationships are present in most duplex steels. It has been shown that the populations of the orientation relationships differ due to the thermal and mechanical treatment and this influences mechanical properties. A large frequency of the special orientation relationships decreases flow stresses by about $15 \%$ [4].

It has also been reported [5] that at intermediate temperatures in the range $300-400^{\circ} \mathrm{C}$, an increase in the flow stress

\footnotetext{
* Corresponding author. Tel.: +48-22-660-8707; fax: +48-22-660-8514. E-mail address: wiziel@inmat.pw.edu.pl (W. Zieliński).
}

and a significant embrittlement has been noticed. This was attributed to the structure of the ferrite where Cr-rich and Fe-rich domains appear, often accompanied by the precipitation of a (Ni, Si and Mo)-rich G-phase.

A fruitful technique for studying the role of grain boundaries in the plastic deformation is in situ electron microscopy deformation. For example, an evidence of the dislocation generation from the grain boundary as a result of the slip transfer in stainless steel was reported [6].

\section{Experimental details}

A ferritic-austenitic bicrystal and ferritic-austenitic duplex steel were investigated in this work. The $\alpha / \gamma$ bicrystal has been produced by bonding monocrystals

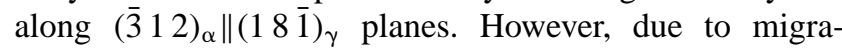
tion of the boundary, the real orientation was found to be $(\overline{3} 12)_{\alpha} \|(04 \overline{1})_{\gamma}$. The orientation relationship between the phases is close to the Kurdiumov-Sachs orientation relationship with a deviation of $6 \pm 0.5^{\circ}$. For this orientation relationship, there are two easy slip planes in both phases, $\left(\begin{array}{lll}1 & 1 & \overline{1}\end{array}\right)_{\gamma}$ and $\left(\begin{array}{lll}\overline{1} & 1 & 0\end{array}\right)_{\alpha}$, which are nearly parallel to each other and are inclined by $\approx 45^{\circ}$ to the bicrystal axis. A detailed description of the manufacture of the bicrystal is published in [7].

The duplex steel has been produced by annealing the alloy at $1260^{\circ} \mathrm{C}$ for $30 \mathrm{~min}$ in vacuum, followed by oil quenching, which produced a ferritic structure with coarse grains 
of $1 \mathrm{~mm}$ mean size. Additional annealing at $960^{\circ} \mathrm{C}$ for $1 \mathrm{~h}$ followed by oil quenching produced the duplex steel containing austenite grains of $7 \mu \mathrm{m}$ length and $1 \mu \mathrm{m}$ width embedded in the ferrite.

The in situ deformation experiments were performed by conventional and high-voltage transmission electron microscopy (CTEM, HVTEM). The CTEM experiments were performed on standard specimens of $3 \mathrm{~mm}$ diameter of biand polycrystals, using a standard straining stage at an accelerating voltage of $100 \mathrm{kV}$. The specimens were prepared by double-jet polishing the initial discs of $0.1 \mathrm{~mm}$ thickness. The discs had been cut with a wire saw from a rod prepared by electric discharge machining. The HVTEM experiments were performed at an accelerating voltage of $1 \mathrm{MV}$, using a quantitative double-tilting straining stage for room temperature [8]. Microtensile specimens of polycrystalline duplex steel were prepared from platelets $8 \mathrm{~mm} \times 2 \mathrm{~mm} \times 0.1 \mathrm{~mm}$ in size by two-step electrolytic double-jet polishing between platinum masks. In both cases, the electrolyte used for electropolishing consisted of $95 \%$ acetic acid and 5\% perchloric acid.

\section{Results and discussion}

The CTEM in situ straining experiment performed on the ferritic-austenitic bicrystal with $6.2^{\circ}$ misorientation from the Kurdiumov-Sachs orientation relationship revealed a dislocation activity in the austenite at the very beginning of the plastic deformation as presented in Fig. 1. At the first stage
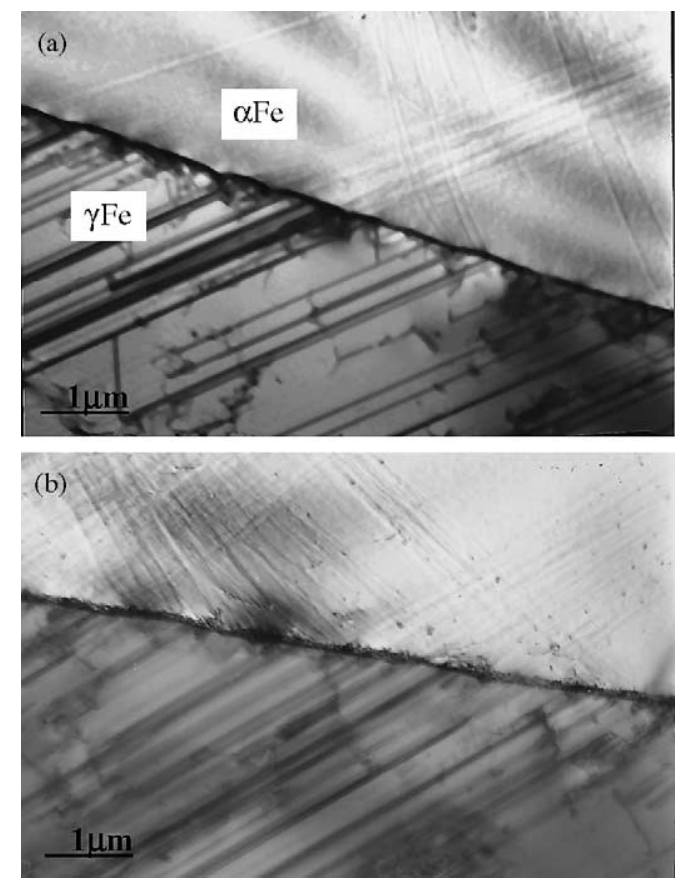

Fig. 1. Evolution of the dislocation structure during deformation of the austenitic-ferritic bicrystal. (a) First stage of deformation at $\varepsilon_{1}$ and (b) second stage of deformation at $\varepsilon_{1}+\varepsilon_{2}$.

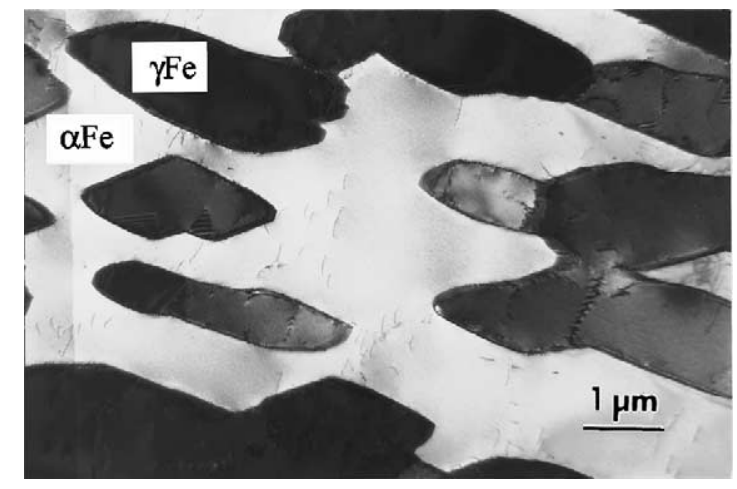

Fig. 2. TEM image of the structure of the ferritic-austenitic duplex steel.

of deformation at $\varepsilon_{1}$, shown in Fig. 1a, a large number of stacking faults appeared in the austenite indicating the activity of partial dislocations. Fig. $1 \mathrm{~b}$ presents the dislocation structure produced in the second stage of deformation at eps $\varepsilon_{1}+\varepsilon_{2}$. Here, slip is distributed rather uniformly in both phases. One may expect that dislocation sources were activated in the ferrite at the grain boundary due to the local stress concentration caused by dislocation pile-ups in the austenite. However, it may be stressed that the plastic deformation of the bicrystal is characterized by a uniform distribution of strains in the austenite as well as in the ferrite.

Fig. 2 presents the microstructure of the investigated duplex steel with grains of austenite embedded in the ferritic matrix. A characteristic feature of the austenite grains is their geometric shape with ledges at the phase boundaries. Stresses may concentrate at these ledges enhancing the dislocation activity.

Fig. 3 shows images of the microstructure of the austenite and ferrite with a ledge at the boundary in the early stage of deformation. There is a misorientation of $2^{\circ}$ from the crystallographic Kurdiumov-Sachs relation between the austenite and ferrite. Fig. 3a presents the dislocation structure in the austenite grain obtained by tilting the specimen in the goniometer by $17^{\circ}$ to yield a good diffraction contrast at $\mathbf{g}=\left(\begin{array}{ll}0 & 02\end{array}\right)$. The microstructure with a number of stacking faults indicates the activity of partial dislocations. Fig. 3b shows an image of a region in the ferrite near the ledge, where dislocation activity was expected during the in situ straining. The specimen was tilted by $6^{\circ}$ to obtain a good diffraction contrast in the ferrite with $\mathbf{g}=\left(\begin{array}{lll}0 & 1 & 1\end{array}\right)$. Using the $\mathbf{g} \cdot \mathbf{b}=0$ criterion for contrast extinction, the dislocations in the ferrite were identified to have screw character with Burgers vectors of $a / 2\langle 111\rangle$. The bowed-out dislocations in the ferrite indicate that their source is at the ledge. The shape of the stacking faults in the austenite points at slip transfer from the austenite to the ferrite.

Fig. 4 shows a dynamic sequence of slip transfer from the austenite to the ferrite through a boundary with a random orientation relationship. The orientation between the austenite and ferrite deviated by $24^{\circ}$ around the $[0.41,0.75, \overline{0.52}]$ axis from the special Kurdiumov-Sachs orientation relationship. 

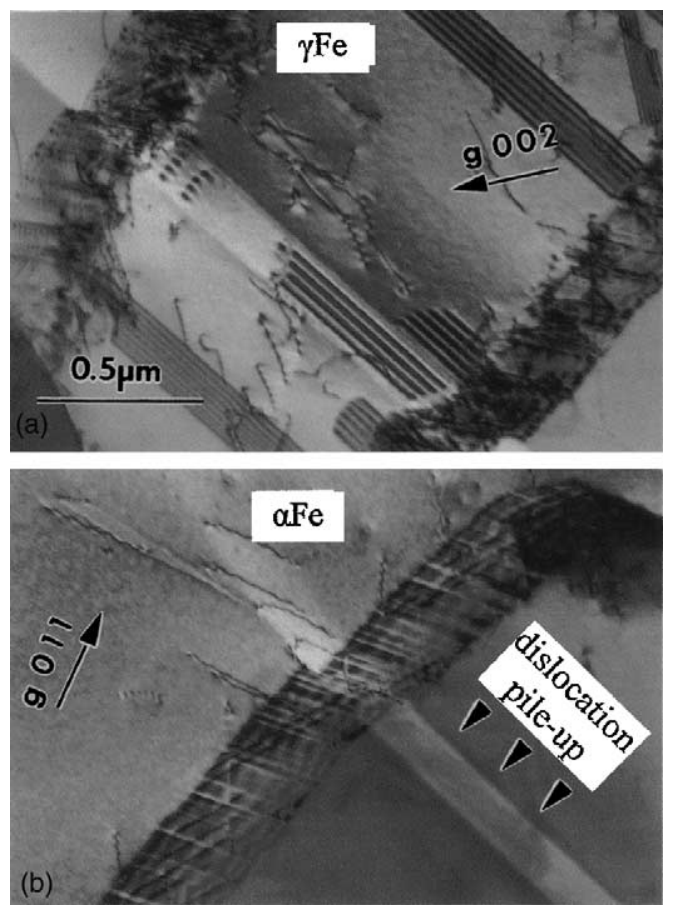

Fig. 3. Dislocation structure near the ledge at the austenitic-ferritic boundary. (a) Structure in the austenite, $\mathbf{g}=\left[\begin{array}{lll}0 & 0 & 2\end{array}\right] \gamma \mathrm{Fe}$ and (b) structure in the ferrite, $\mathbf{g}=\left[\begin{array}{lll}0 & 1 & 1\end{array}\right] \alpha \mathrm{Fe}$.

The slip traces of the dislocations in the ferrite do not follow the direction of the dislocation pile-up in the austenite indicating the incompatibility of the slip systems in the two phases. The weavy slip traces, the moving dislocations trails at the surfaces of the thin TEM foils, point at the easiness of cross-slip. The dislocations in the ferrite spread over large areas creating a uniform distribution of strain.

Additional information on the duplex steel was obtained from the HVTEM in situ straining experiments. Video recordings show the operation of a single-ended fixed dislocation source in the austenite. The emission of a great number of dislocations leads to a highly localized strain. As described above, in the case of special orientation relationship between the austenite and ferrite, where easy-slip systems have the same orientation in both phases, the strain becomes localized. The specific percolating structure of the duplex steel with small austenite grains included in very large grains of ferrite may be a reason for the reduced plasticity when special orientation relationships are dominant.

The HVTEM in situ experiments show also the slip transfer from the austenite to the ferrite for boundaries with random orientation relationships. An increasing number of dislocations piles up in the austenite, while other dislocations are emitted from the boundary into the ferrite. Afterwards, they slip and cross-slip over large areas of the grain. Many dislocations in the ferrite move in a jerky manner. The cross-slip processes lead to the creation of dislocation loops and debris as well as to a dislocation multiplication resulting in work hardening.
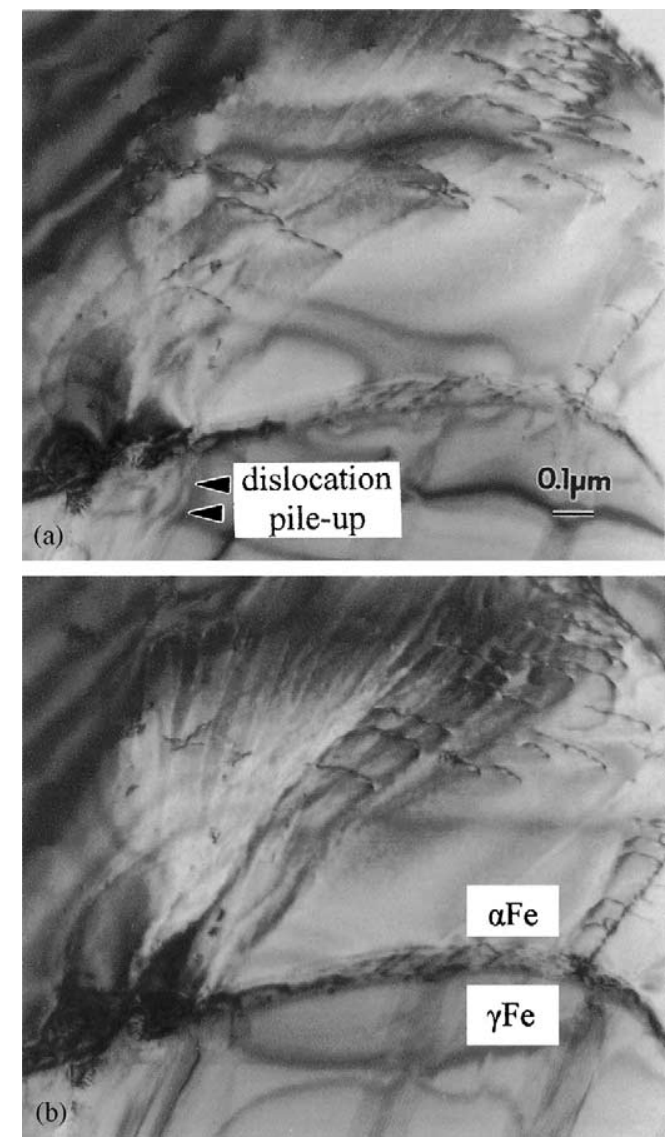

Fig. 4. Dynamic sequence of the dislocation transfer from austenite to ferrite through a boundary with a random orientation relationship. (a) First stage of deformation at $\varepsilon_{1}$ and (b) second stage of deformation at $\varepsilon_{1}+\varepsilon_{2}$.

The results obtained from the HVTEM in situ straining experiments indicate two factors responsible for the higher flow stress of duplex steel with dominating random orientation relationships between the austenite and the ferrite. Firstly, the flow stress is higher due to the higher stress required for transferring slip between incompatible slip systems. Secondly, the expanding dislocation loops, produced by the cross-slip of gliding dislocations in the ferrite, lead to relatively homogeneous deformation and work hardening. Thus, a higher stress is required to transfer the dislocations from pile-ups in the austenite to the ferrite.

\section{Conclusions}

The TEM in situ observations yielded details about the evolution of the dislocation structure and the slip transfer mechanism through the boundaries in the ferritic-austenitic duplex steel. In the case of special orientation relationships, the slip traces in the ferrite, produced by the dislocations emitted from the boundary, indicate the compatibility of the easy slip systems in the two phases which favors a strong localization of strain. In the case of random orientation 
relationships, the incompatibility of the easy-slip systems in the austenite and ferrite results in the cross-slip of dislocations emitted from the boundary into the ferrite grains leading to multiplication and the formation of dislocation loops and debris. The high flow stress of duplex steel can be attributed to the particular slip transfer mechanism related to the random orientation relationships between the austenite and ferrite.

\section{Acknowledgements}

This work was supported by the Polish Committee of Scientific Research under contract 7 T08A 03919 for WZ and by the Franco-Polish research cooperation program for WS. One of the authors (WZ) wishes to acknowledge the support given by Prof. Jan Dutkiewicz and the creative atmosphere and hospitality of the Max-Planck-Institut für Mikrostruk- turphysik in Halle, Germany, where part of this work was done. Prof. Krzysztof J. Kurzydłowski is acknowledged for valuable remarks.

\section{References}

[1] M.W. Grabski, J. Phys. France 46 (C5) (1988) 497.

[2] A.P. Sutton, R.W. Balllufi, Interfaces in Crystalline Materials, Clarendon Press, Oxford, 1996, p. 730.

[3] L. Priester, Interf. Sci. 4 (1996) 205.

[4] W.A. Świątnicki, W. Zieliński, Mater. Sci. Forum 294-296 (1999) 641.

[5] B. Verhaeghe, F. Louchet, B. Doisneau-Cottignies, Y. Brechet, J.-P. Massoud, Phil. Mag. A 76 (1997) 1079.

[6] K.J. Kurzydłowski, R.A. Varin, W. Zieliński, Acta Metall. 32 (1984) 71.

[7] S. Hashimoto, S. Kato, T. Mimaki, S. Miura, J. Phys. (France) 51 (C1) (1990) 831.

[8] U. Messerschmidt, F. Appel, Ultramicroscopy 1 (1975) 17. 